\title{
Characterization of students admitted to medical-surgical specializations at The University of Cartagena, 2016-2
}

\author{
Virna Caraballo Osorio ${ }^{\# 1}$, Rita Sierra Merlano ${ }^{\# 2}$, Marlene Duran Lengua ${ }^{\# 3}$ \\ ${ }^{\text {\# }}$ School of Medicine, Universidad de Cartagena \\ 130015 Cartagena de Indias, D. T. y C., Colombia \\ 11vcaraballoo@unicartagena.edu.co, ${ }^{2}$ rmagola@unicartagena.edu.co \\ ${ }^{3}$ mduranl@unicartagena.edu.co
}

\begin{abstract}
In Colombia there are currently few quotas to perform a surgical specialization, in comparison with the number of medical graduates. A descriptive study whose objective was to conduct a sociodemographic and academic-investigative characterization of students admitted to medical-surgical specializations at the University of Cartagena in 2016. Enrolled a total of 1420 doctors who competed for 55 quotas available in twelve medical-surgical specializations. Evaluated scores on the test of knowledge, resume and interview of the admitted 55 (3.8\% of the total) and was also carried out a survey which included socio-demographic aspects. The maximum score of the knowledge test was 61 (of 80 possible) which represents $76.25 \%$ of the total. With regard to the rating of the resume were admitted with scores of 1.3 points, the average resumes was 4.79. The interview scores were higher with an average of 9.39 (of 10 possible). The most preferred medical specialty was internal medicine $(21.8 \%) \mathbf{1 2 . 7 4 \%}$ compared to $\mathbf{9 . 0 6 \%}$ in men and women respectively, followed by pediatrics $(\mathbf{1 4 . 5 \% )}$, women were inclined for Internal Medicine and Pediatrics and did not enroll in any specialty of Neurosurgery, Orthopedics and traumatology and General Surgery. In general, those admitted come from different regions of Colombia but most are from the Atlantic coast.
\end{abstract}

Keywords: knowledge test, interview, specialty, sociodemographic profile.

\section{INTRODUCTION}

Medical education requires undergraduate students to study a wide range of medical-surgical specializations. It is often assumed that students do not make career choices until after they graduate from medical school. However, not only those who enter the medical school, but even the applicants of medical school, often have strong preferences for or against some medical careers [1]. With the continued evolution of medical care delivery and advances in medical technology, the mix of appropriate specialties within the medical workforce is still debated. Studying career preferences can help provide important information to help plan educational programs, prioritize and plan for the provision of adequate health care. The preference of medical-surgical specializations chosen by medical graduates plays an important role in the future workforce in the health system, especially in times of excess or lack of supply of doctors [1].

In Colombia the offer of medical-surgical specialization programs has increased in recent years by just over 150\%, from 21 in 1992 to 64 in 2015 and graduated from 3,500 to 4,000 physicians every year. According to the Ministry of Health of Colombia in 2009 there were 72,544 physicians (16 professionals per 10,000 inhabitants). The distribution of physicians by geographical area in Colombia shows a concentration in Bogotá DC, Valle del Cauca, Santander and in departments such as Guainía, Vaupés, Vichada and Chocó, with a proportion below the average (one physician per 10,000 inhabitants) [2]. 29 Higher Education Institutions (HEIs) offer medical-surgical specializations. At the moment there are approximately 180 different names of medical-surgical specializations, which in a first exercise could be grouped into 94 by similar professional profile (Escobar Gaviria R. Basic descriptors of Colombian medicine programs 2015, ASCOFAME). In the study published by the Panamerican Health Organization (PAHO) in 2012 in Colombia, the Ministry of National Education (MEN) has registered 82 medical specialties and 852 annual quotas, showing a large dispersion of quotas by specializations [3], [4].

The universities with the highest number of graduated professionals are in the Atlantic Coast, which is probably associated with a greater interest in the profession, lower costs of academic programs and a greater number of university places, among other factors [2]. In 2015, in the first and second semester 10,044 and 11,133 applicants were presented respectively, and 400 and 299 were enrolled, that is to say, the ratio of enrolled students was 13 to 1 and 20 to 1 respectively. This situation means that many of the physicians emigrate to be able to develop a specialty abroad (Escobar Gaviria R. Basic descriptors of the medical programs of Colombia 2015, ASCOFAME). The limited offer of quotas, the scarcity of quotas in public universities and the high value of enrollments in private universities confer a "high value" to a quota in a surgical medical 
specialization, especially in public universities, and traditionally, in these Universities it is done under the principles of equality and transparency [5].

On the other hand, Dr. Ricardo H. Escobar Gaviria, editor of the document derived from the working tables of the XXXI Extraordinary General Assembly of ASCOFAME held on November 26 and 27, 2015, considers that the number of quotas is limited by the resources for the formation of the students, particularly in the teaching-service scenarios (human, physical, technological, welfare, research). The hospital and sector crisis is an obstacle, as well as the conflicts of interest of scientific societies. The public hospital network has problems to sustain the programs; this situation forces to contract with private institutions that have no vocation for teaching; must pay per student and have the concurrence of students of various programs. In the city of Cartagena there are currently three faculties of Medicine, two private and one public that graduate approximately 150eachyear and of these, two Faculties (one private and one public offer medical surgical specializations).

In Colombia, medical training lasts 6 years divided into three years of preclinical training and 3 years of clinical training, after which you get the title of General Physician, or Physician for other universities. Subsequently, the year or six months of compulsory social service that corresponds to a practice time as a newly qualified physician, which allows obtaining the professional card to practice the profession in the country. Subsequent studies correspond to postgraduate studies that can last between three and four years for specialties and two years for subspecialties. There are also postgraduate modalities of high technical quality such as masters and doctorates, or specializations in administrative areas [6].After obtaining your professional card, the path for the aspirants to specialists begins a tour from a University to another, presenting exams and looking for references that will help you obtain the best results in the interviews of each university and access a site for begin theirs specialization.[7].

In the Call 2016-2 for medical specialties of the University of Cartagena, a total of 1420 physicians were registered, of whom 55 were chosen, for the 12 medical surgical specializations offered. In the selection process, applicants submitted a written general knowledge test that had a value of $80 \%$. For five years, the knowledge test has been carried out by the University of Antioquia, preparing a list of eligible candidates. The number of eligible persons is twice the number of places offered by medical surgical specialization (55 places in total for this call). Eligible students presented their resume (10\% of the total score) and attended an interview with the Coordinators, teachers of the specialization and a teacher of the basic area (10\% of the total score). With the sum of the scores obtained in the different tests, the 55 admitted to the Surgical Medical Specialties of the University of Cartagena were obtained.

There is a research on the process of admission to medical surgical specialties in the country and there are no general characteristics that a student admitted must have according to the parameters established for the 2016-2 Call. Currently, there is no local research that has investigated fundamental aspects of the process, which relate academic aspects, which augur more likely to access a quota in a medical-surgical specializations of the University. The general characteristics of the admittedthat is being selected with the parameters defined in the 2016-2 Convocation Guide are also unknown. The objective of this research was to characterize aspects, sociodemographic and academic-investigative of those admitted to medical-surgical specializations, and know how far they move away from and / or approach compliance with the criteria established by the University of Cartagena.

\section{MATERIALS AND METHODS}

A. A descriptive study was carried out that included those admitted to the medical specialties of the University of Cartagena corresponding to $3.8 \%$ of the total number of applicants who participated in the call, which is equivalent to 55 admitted.

The selection of those admitted was based on three fundamental aspects, related to academic, investigative factors, professional experience and socio-demographic aspects. These aspects were evaluated in several stages and instruments designed by the Postgraduate Department, which are carried out in chronological order as described below:

\section{B. Admission test or knowledge}

This is done by the University of Antioquia and evaluates general medical knowledge. It has a value of $80 \%$ of the total. Eligible applicants are the highest scores, resulting in a greater number of selected ones since in most of the scores they are repeated. Giving place to double the quotas offered by Specialization.

\section{Evaluation format of resumes}

This format consists of questions that aim to know aspects related to research, academic achievements and work experience, has a value of $10 \%$. 


\section{Directed interview}

It is designed to know socio-economic cultural aspects of the applicant, in addition to analyzing psychological aspects based on a psychotechnical test conducted by the Department of Psychology of the University, however this psychological characterization does not provide points in the selection and choice of the applicant.

With the sum of the totals obtained, those admitted in the 2016-2 Call for medical-surgical specializations of the University of Cartagena were chosen, who had to complete some established requirements. For this study, a survey was conducted of the 55 physicians admitted to the 2016-2 Call for medical specialties of the University of Cartagena. The survey designed by the graduate department of the faculty points to a prior self-evaluation of each admitted physician.

\section{RESULTS AND DISCUSSIONS}

The demands in the training of medical specialists is increasing, given the increase of diseases with unknown causality and the growing technological development in the medical field. In this study of a total of 1420 applicants, 3.8\% were selected equivalent to 55 admitted. The University of Cartagena leads the training of medical specialists in the Colombian Caribbean region, which represents a responsibility and commitment to society. This study determined the transparency of the selection process, which selects those professionals with the highest scores in terms of established criteria for the selection and admission of the future resident of the specialty programs offered by the University. The selection criteria do not differ from those of other universities in the country, such as, among others, a knowledge test.

With regard to the marital status of those admitted, $87.27 \%$ are single, $83.64 \%$ have no children, and $76.36 \%$ said they were Catholic. With reference to the city where they lived before the convocation, it was found that 10 (18.18\%) lived in Medellín and 9 (16.36\%) in Cartagena;of the total admitted 47 (85.45\%) live in capital cities throughout the country, which reflects that doctors are located preferably in capital cities and medium-sized populations, only 8 (14.55\%) live in small populations. Of the 55 admitted, 10 (18.18\%) lived in Medellín, 9 (16.36\%) lived in Cartagena, 5 (9.09\%) came from Bucaramanga, 5 (9.09\%) from Bogotá, 5 (9.09\%) from Valledupar, 2 ( 3.64\%) from Cali, 2 (3.64\%) from Pereira, 2 (3.64\%) from Cúcuta, 2 (3.64\%) from Montería, one (1.82\%) from Armenia, 1 (1.82\%) from Barranquilla, 1 (1.82\%) ) from Sincelejo, 1 (1.82) from Ibagué, 1 (1.82\%) from Manizales and 8 (15.55\%) came from different populations of different regions of the country.

\section{a. Admission process Knowledge test}

The maximum score of the knowledge test was 61 (of 80 possible) which represents $76.25 \%$ of the total, which shows that it was a test with a high level of complexity. With regard to the rating of the resume were admitted with scores of 1.3 points. It should be noted that the instrument grants a maximum of 10 points, but does not have a minimum criterion that declares exclusionary to the admitted, the average in resumes was 4.79. The interview scores were higher with an average of 9.39 (of 10 possible). Making the sum of the scores of the three criteria evaluated, the maximum score was 72.50 and the minimum of 54.7 with an average of 66.15 (100) which is relatively low.

\section{b. Results of the admission process}

The maximum total score of the admitted ones was of 72.5 and the minimum was of 54.7 with an average of 66.15. The maximum, minimum and average results of the knowledge test, the resume evaluation and the interview are shown in Table 1.

Table 1. Results of the Selection Process of those Admitted to the Medical-SurgicalSpecializations of the University of Cartagena, 2016-2.

\begin{tabular}{ccccc}
\hline & Value in \% & Highest score & Lowest Score & Average \\
\hline Knowledge test & 80 & 61 & 42 & 51.96 \\
CV & 10 & 8.6 & 1.3 & 4.79 \\
Interview & 10 & 10 & 6 & 9.39 \\
Total & $100 \%$ & 72.5 & 54.7 & 66.15 \\
\hline
\end{tabular}

\section{c. Socio-demographic characteristics}

Among the socio-demographic aspects, which were analyzed in order to characterize the admitted candidate was the age of the applicants which fluctuated between 40 and 23 years the average was 30.4 years. Taking into account that physicians graduate between 23 and 24 years of undergraduate, we could consider that most of those admitted have several years of graduates and that most of those admitted took several years to enter a medical-surgical specialization. This coincides with that reported by Echeverri-Raad J. who determined that the cohorts do not represent newly graduated doctors, since the average age of graduation in Latin America in the medical career is around 23 to 26 years [5]. 
With regard to marital status, most were single at the time of admission, married and those who lived together in union reached less than $13 \%$. Emphasizing the religion that professes a high percentage admit to being Catholic. Religion deals with issues that are relevant to medicine, such as human suffering and the dilemma of life and death, as well as being associated with spirituality. In order to investigate the intensity of religious influence on attitudes towards patients, one study applied two questionnaires to 324 doctors working in public hospitals in Poland [8]. There was a statistically significant difference between the degree of religiosity between surgical and non-surgical specialties, favoring the former. There was also a significant positive correlation between a religiosity scale and the dimensions of holism, empathy and altruism. Regarding questions about religious faith, the majority agreed that this attribute allows them to better cope with professional obligations, and that awareness of the presence of God helps in difficult situations. Although this study did not find this association, the finding of the study mentioned above showed that the sociocultural characteristics of physicians can influence attitudes towards patients. These characteristics cannot be ignored and must be investigated further.

In Table 2, with respect to gender, $60 \%$ of those admitted are men, this figure could be related to the relative values of men and women in the Faculties of Medicine. Although there are more medical women every day, in undergraduate there are still many more men than women. This phenomenon does not go unnoticed in the residents admitted in this study, this agrees with studies carried out by other researchers such as [9]. In a study carried out by the University of Barranquilla, it is shown that the prevalence of doctors who aspire to specialize is high, just as the male gender predominates [10].It is noteworthy that some of the medical specialties are more attractive for women and in these the largest admitted are female as is the case with the Pediatrics specialization, where $62.5 \%$ of admitted women.A study conducted at the National University concluded that the probability of being admitted to the program (of Pediatrics) was significantly related in isolation to the age, public or private nature of the IES, and the partial and total grades obtained in the process of admission. This probability was not significantly related to the number of applications made by the applicants $(r=0.09, p=0.0127)$. None of the applicants who applied on three occasions were admitted and $11,26 \%$ of the 42 admitted, achieved it after their second attempt [5]. Previous research demonstrated the tendency of medical students to pursue specialization or postgraduate studies, $95.48 \%$ of the students surveyed would prefer to specialize. The goal of specializing is a legitimate exercise of the talent and knowledge of each person, and undoubtedly, contributes to improving the safety of the medical act, but in Colombia only $28 \%$ of doctors practice as specialists. In the United States and many European countries, $80 \%$ of doctors practice as specialists [11].

Table 2. Characteristics of those Admitted According to Medical-Surgical Specializations.

\begin{tabular}{ccccccccc}
\hline Program & \multicolumn{2}{c}{ Gender } & \multicolumn{2}{c}{ Civil status } & \multicolumn{2}{c}{ Children } & \multicolumn{2}{c}{ Religion } \\
\hline Internal Medicine & 7 & $\mathbf{M}$ & Single & Married & Yes & No & Catholic & Otra \\
Pediatrics & 3 & 5 & 11 & 1 & 2 & 10 & 10 & 2 \\
Gynecology and & 2 & 4 & 4 & 0 & 1 & 7 & 7 & 1 \\
$\quad$ Obstetrics & & & & 2 & 2 & 4 & 5 & 1 \\
General Surgery & 6 & 0 & 6 & 0 & 2 & 4 & 6 & 0 \\
Anestesiology & 5 & 1 & 6 & 0 & 0 & 6 & 5 & 1 \\
Orthopedics and & 4 & 0 & 4 & 0 & 1 & 3 & 3 & 1 \\
traumatology & & & & & & & & \\
$\quad$ Urology & 2 & 2 & 4 & 0 & 0 & 4 & 4 & 0 \\
Otorhinolaryngology & 1 & 1 & 2 & 0 & 0 & 2 & 1 & 1 \\
Radiology and & 1 & 1 & 1 & 1 & 0 & 2 & 1 & 1 \\
diagnostic images & & & & & & & & \\
$\quad$ Pathology & 0 & 2 & 2 & 0 & 1 & 1 & 0 & 2 \\
Psychiatry & 1 & 1 & 2 & 0 & 0 & 2 & 0 & 2 \\
Neurosurgery & 1 & 0 & 1 & 0 & 0 & 1 & 0 & 1 \\
$\quad$ Totals & 33 & 22 & 51 & 4 & 9 & 46 & 42 & 13 \\
Percentages & $\mathbf{6 0} \%$ & $\mathbf{4 0 \%}$ & $\mathbf{9 2 . 7 2 \%}$ & $\mathbf{7 . 2 7 \%}$ & $\mathbf{1 6 . 3 6 \%}$ & $\mathbf{8 3 . 6 4 \%}$ & $\mathbf{7 6 . 3 6 \%}$ & $\mathbf{2 3 . 6 3 \%}$ \\
\hline
\end{tabular}


The study carried out by the center of projects for the development (Cendex) of the Javeriana University with the Ministry of Health and Social Protection, describes the most representative indicators regarding the shortage of specialists in Medicine: few quotas to specialize, low salaries for specialists, control of specialists in relation to the number of graduates, lack of incentives to specialize, among others. Hence the concern that the education system does not provide the necessary quotas for the training of specialists required to serve the population. Even so, with the efforts of educational institutions, there has been an increase of $25 \%$ of graduates of medical specialties in the last decade [6].

Khader et al., [12] studied the factors that affect the students of medical specialties in Jordan, the average age was $21.1 \pm 2.0$ years, approximately one third (36\%) were females and only 23 students were Christians. Many researchers have tried to determine factors that influence students' specialty preferences. Some have postulated that the main influences were the personal characteristics of the students, as controllable lifestyles, while others have arisen other factors related to the characteristics of the medical school, such as the orientation to research. Vaidya et al., [13] reported in their study of the relationship between the specialty and the temperament of medical postgraduate students. They found that the average age was 27.49 years, there were $58.1 \%$ men and $38.4 \%$ women, $3.4 \%$ did not report their gender. The sample was ethnically diverse: $(41.3 \%)$ were European American, (33.4\%) were Asian American, (5.4\%) were African American, (1.9\%) were Hispanic and (1.9\%) were Arab-American. Regarding the factors that influence the relationship of the medical career (for or against), the most frequently cited is the quality of life, the type of activity (private or public hospital), contact with patients and the type of medical activity.

Table 3 shows that those admitted came from different regions of the country, a higher percentage (33\%) did the undergraduate degree at the University of Cartagena and only 5.45\% did the undergraduate at the University of Antioquia. It could be believed that the graduates of the University of Antioquia have an advantage because they are the ones who prepare the knowledge exam and in them the knowledge and behaviors followed by their students during their training are evaluated. The figures show that there are no advantages with being a graduate of the University of Antioquia with respect to admission to a surgical medical specialty at the University of Cartagena.

Table3. Egress University of the Admitted

\begin{tabular}{ccc}
\hline University of Egress & \# Of Admitted & Percentage \\
\hline University of Cartagena & 18 & $33 \%$ \\
Industrial University of Santander & 5 & $9.09 \%$ \\
University of Magdalena & 5 & $9.09 \%$ \\
University of Antioquia & 3 & $5.45 \%$ \\
University of the Valle & 3 & $5.45 \%$ \\
Technological University of Pereira & 1 & $1.82 \%$ \\
University of Caldas & 1 & $1.82 \%$ \\
University of Tolima & 1 & $1.82 \%$ \\
University of Quindío & 1 & $1.82 \%$ \\
University of Sinú & 2 & $3.64 \%$ \\
San Martin University & 5 & $9.09 \%$ \\
Metropolitan University & 2 & $3.64 \%$ \\
Patin American School of Medicine & 1 & $1.82 \%$ \\
Pedagogical and Technological University of Colombia & 1 & $1.82 \%$ \\
Juan N Corpas Foundation & 1 & $1.82 \%$ \\
Central University of the Valley & 1 & $1.82 \%$ \\
Autonomous University of Bucaramanga & 1 & $1.82 \%$ \\
University of Santander & 1 & $1.82 \%$ \\
Cooperative University of Colombia & 1 & $1.82 \%$ \\
\hline
\end{tabular}

In Table 4, it is observed that $72.7 \%$ of those admitted came from public Universities. This is consistent with that found in other studies in which the probability of being admitted was related in isolation to the public or private nature of HEIs [5]. The most preferred medical specialty was internal medicine (21.8\%) $12.74 \%$ compared to $9.06 \%$ in men and women respectively, followed by pediatrics (14.5\%). Men prefer Internal Medicine and General Surgery, while women were inclined towards Internal Medicine and Pediatrics and did not enroll in any specialty of Neurosurgery, Orthopedics and Traumatology and General Surgery.Khader et al., 
[12] stated that the most preferred medical specialty among male students was surgery, followed by internal medicine and orthopedics, and while the most preferred by female students was obstetrics and gynecology followed by Pediatrics and surgery. A total of 146 (52\%) of the male students expressed interest in surgery compared to $15 \%$ of the students ( $\mathrm{p}<0.005$ ). $31 \%$ of students preferred gynecology compared to $1 \%$ of male students. Men (15\%) and women (14\%) were equally likely to express interest in internal medicine. The students showed little interest in other specialties, including orthopedics ( $8 \%$ male versus $3 \%$ female), ophthalmology ( $6 \%$ male versus $9 \%$ female) and dermatology (1\% male versus $4 \%$ female). While $3 \%$ of women expressed interest in anesthesiology, no male student did. Other specialties such as radiology, psychiatry, public health, family medicine and basic sciences were not preferred by almost all students.

Table 4. Character of the University and Average Greater than 4 of the Admitted Ones in the Call 2016-2 According to Medical-Surgical Specializations

\begin{tabular}{ccccc}
\hline Program & \multicolumn{2}{c}{ University of Egress } & \multicolumn{2}{c}{ Average $>\mathbf{4}$} \\
\hline & Public & Private & Si & No \\
Internal Medicine & 8 & 4 & 6 & 6 \\
Pediatrics & 4 & 4 & 5 & 3 \\
Gynecology and Obstetrics & 4 & 2 & 0 & 6 \\
General Surgery & 3 & 3 & 1 & 5 \\
Anesthesiology and reanimation & 6 & 0 & 4 & 2 \\
Orthopedics and Traumatology & 2 & 2 & 1 & 3 \\
Urology & 4 & 0 & 3 & 1 \\
Otorhinolaryngology & 2 & 0 & 1 & 1 \\
Radiology and Dx images & 2 & 0 & 1 & 1 \\
Pathology & 2 & 0 & 1 & 1 \\
Psychiatry & 2 & 0 & 0 & 2 \\
Neurosurgery & 1 & 0 & 0 & 1 \\
Totals & 40 & 15 & 23 & 32 \\
Percentages & $\mathbf{7 2 . 7 3 \%}$ & $\mathbf{2 7 . 2 7 \%}$ & $\mathbf{4 1 . 8 2 \%}$ & $\mathbf{5 8 . 1 8 \%}$ \\
\hline
\end{tabular}

$87.27 \%$ of those admitted made the obligatory social service (Table 5). $58.1 \%$ had an accumulated undergraduate average of less than 4 . The majority (61.8\%) had no publications and did not belong to a research group (81.82\%). $49 \%$ of those admitted had at least a diploma program. With respect to the competence of a second language, 87.27\% did not have an international certification of English with level B2 or higher.

\begin{tabular}{|c|c|c|}
\hline Academic-investigative aspect & Admitted & $\%$ \\
\hline G. Research & 10 & 18.18 \\
\hline Diploma Programa & 27 & 49.09 \\
\hline Specialists & 2 & 3.64 \\
\hline Magister & 1 & 1.82 \\
\hline English level B2 & 7 & 12.73 \\
\hline Publications & 21 & 38,18 \\
\hline Obligatory Social service & 48 & 87.27 \\
\hline
\end{tabular}

\section{CONCLUSION}

Those admitted with higher scores in this consolidated test do not guarantee that they are those that have predictable characteristics for better performance during residency. Regarding the sociodemographic study, the average age was 30.4 years. The largest number of admitted were men, most profess the Catholic religion, before the call a high percentage of admitted living in Medellin, graduates of public universities. Regarding the research area, the majority did not have publications or belonged to a research group, did not have additional studies or certification of English with level B2 or higher. The most preferred medical specialty was internal medicine followed by pediatrics, women wereinclined for Internal Medicine and Pediatrics. In general, those admitted come from different regions of Colombia but most are from the Atlantic coast. 


\section{REFERENCES}

[1] B. Wright, I. Scott,W. Woloschuk,F. Brenneis,J. Bradley. Career choice of new medical students at three Canadian universities: family medicine versus specialty medicine. Canadian Medical Association Journal, vol. 170, no.. 13, pp. 1920-1924, 2004.

[2] J. Sánchez. La formación médica en Colombia. Educación y Desarrollo Social, vol. 8, no. 2, pp. 168-183, 2014.

[3] Periago MR. La renovación de la atención primaria de salud en las Américas: la propuesta de la organización panamericana de la salud para el siglo XXI. Revista Panamericana de Salud Pública, vol. 21, no. (2-3), pp. 65-8, 2007.

[4] J. Macinko,H. Montenegro,C. Nebot, C.Etienne. La renovación de la atención primaria de salud en las Américas. Rev Panam Salud Publica, vol. 21, no. (2/3), pp. 73-84, 2007.

[5] R.J. Echeverry. Aspectos generales y académicos de los* aspirantes y los* admitidos a la especialidad de pediatría de la Universidad Nacional de Colombia. Revista de la Facultad de Medicina, vol. 63, no. 1, pp. 33-45, 2015.

[6] J.S. Castillo. La formación médica en Colombia. Revista Educación y Desarrollo Social, vol. 8, no. 2, pp. 168-83, 2014.

[7] A.P. Patiño. Centralizar el ingreso a residencias médicas. Morfolia, vol. 8, no. 3, pp. 19-20, 2017.

[8] J. Pawlikowski,J.J. Sak,K. Marczewski.Physicians' religiosity and attitudes towards patients. Ann Agric Environ Med, vol. 19, pp. 503-507, 2012.

[9] K.A. Johannessen,T.P. Hagen. Individual and hospital-specific factors influencing medical graduates' time to medical specialization. Social Science \& Medicine, vol. 97, pp. 170-175, 2013.

[10] G. De la Hoz. Modelo para Evaluar las Competencias Psico profesionales de los Medicos aspirantes a la Especialización MédicoQuirurgica. Biociencias, vol. 6, no. 1, 165-173, 2016

[11] C.T. Serna Médicos generales:¿ Una respuesta al pasado? Revista Colombiana Salud Libre, vol. 3, no. 2, pp. 157-163, 2015

[12] Y. Khader, D. Al-Zoubi, Z. Amarin, A. Alkafagei, M. Khasawneh, S. Burgan, M. Omari. Factors affecting medical students in formulating their specialty preferences in Jordan. BMC medical Education, vol. 8, no. 1, 1-7, 2008.

[13] N.A. Vaidya, F.S. Sierles, M.D. Raida, F.J. Fakhoury, T.R. Przybeck,C.R. Cloninger. Relationship between specialty choice and medical student temperament and character assessed with Cloninger Inventory. Teaching and learning in medicine, vol. 16, no. 2, pp. 150-156, 2004.

\section{AUTHORS PROFILE}

Virna Caraballo Osorio. Medical physician, Specialist in Pathology, Specialist in Education, Professor of Pathology in Universidad de Cartagena.

Rita Sierra Merlano, Medical physician, Specialist in Internal Medicines, Specialist in Rheumatology, Ph. D in Education, Professor of Internal Medicine in Universidad de Cartagena.

Marlene Duran Lengua, Magister in Pharmacology, Specialist in Biochemistry, $\mathrm{PhD}$ in Biomedical Sciences,Professor of Pharmacology in Universidad de Cartagena 